\title{
EÇA DE QUEIRÓS ENTRE GÊNEROS
}

Ana Lúcia Branco ${ }^{1}$

Elizabete Ferraz Sanches ${ }^{2}$

RESUMO: O artigo objetiva demonstrar as características do gênero conto, em uma primeira instância, para, em seguida, abordar as questões teorizadas em duas obras de Eça de Queirós: "No Moinho" e O Primo Basílio.

PALAVRAS-CHAVE: Gêneros literários; Eça de Queirós; conto, romance

ABSTRACT: The paper intends to show, at first, the characteristics of the short story style of writing, so as to approach, in a second moment, the theoretical questions in two works of Eça de Queirós: "No moinho" e O Primo Basílio.

KEYWORDS: Literary genres; Eça de Queirós; short story; novel

Desde os primórdios da crítica literária tem-se encontrado dificuldades no que diz respeito à classificação dos gêneros. Nos primórdios os gêneros eram épico, lírico e dramático. Todavia, percebe-se que suas ramificações não poderiam ser ignoradas, afinal, partindo da necessidade do homem de classificar tudo a sua volta, e dentro de si, a criação de "subcategorias" foi quase inevitável. Assim sendo, o grande problema acerca do gênero iniciou-se: como diferenciar, então, a crônica do conto; o romance da novela; o conto do romance?

Esse questionamento serviu como ponto de partida para alguns críticos que tentaram definir esses "subgêneros", utilizando-se de um olhar muito particular, seja em direção à ação, ao tempo, à estrutura, ao espaço, ou até mesmo às personagens.

A análise dessas categorias, em especial a prosa, acaba por permitir um leque de possibilidades. Em outras palavras, não nos parece tão arbitrário o conceito de conto quando Mário de Andrade diz "conto é o que eu chamar de conto", ou então quando encontramos, em um livro de crônicas, um texto que considerávamos do gênero conto. Neste último caso, temos o que chamamos de "contrato com o leitor", se o conto

\footnotetext{
${ }^{1}$ Mestra, em Literatura Brasileira, e atual doutoranda na área de psicanálise e literatura. FFLCH - USP.

${ }^{2}$ Mestranda, em Literatura Brasileira, pela FFLCH - USP.
} 
"Tentação", de Clarice Lispector, estiver em um livro de crônicas, este passará a ser lido como crônica e não como conto.

Em relação à categoria conto e romance, Eça de Queirós, cuja obra é a mais representativa das tensões ideológicas do Realismo português, segundo Abdala Jr e Paschoalin (1990: 109), nos presenteou com o romance O Primo Basílio e o conto "No Moinho", obras que, embora tragam em si o mesmo tema, possuem estruturas distintas, o que nos permite classificá-los em gêneros diferentes. As duas obras serão analisadas paralelamente numa tentativa despretensiosa de buscar elementos conceituais dos dois gêneros, considerando que, do ponto de vista artístico, as personagens e fatos na maior parte de suas narrativas são representados de forma crítica e distanciada, e ressaltando que as produções carregam em sua mimesis dois pólos de tensões ideológicas: “o do sentido mais conservador, que se enraíza em sua origem social, e o reformista, próprio das reivindicações pequeno-burguesas de sua época" (ABDALA Jr. \& PASCHOALIN, 1990: 110).

\section{I - Knock-out versus Pontos}

Júlio Cortázar nos apresenta, em Valise de Cronópio, alguns conceitos de conto que elucidam, em alguns aspectos, essa problemática de gêneros literários, e que podem ser corroborados nas duas obras de Eça de Queirós citadas.

Segundo Cortázar, "o romance ganha sempre por pontos, enquanto que o conto deve ganhar por knock-out" (p. 23). De fato, podemos perceber que o romance nos proporciona um acréscimo de informações que se faz progressivamente, criando indícios das próximas ações, enquanto que o conto, por ser um gênero mais "enxuto", não nos prepara, não nos fornece indícios das ações que se seguirão. É naquele gênero, contudo, que melhor se pode apreender um "vasto inquérito da sociedade portuguesa da época” (ABDALA Jr. \& PASCHOALIN, 1991: 110)

Definido, a princípio, pela ação de contar, algo, portanto, imemorial e anterior à literatura, o conto aqui analisado fixa-se na fase da segunda revolução industrial, sendo o eixo de origem americano-europeu indissoluvelmente ligado aos primeiros balbucios

\footnotetext{
${ }^{3}$ LISPECTOR, C. "Tentação”. In: Felicidade clandestina. Rio de Janeiro: Rocco, 1998.
} 
da indústria cultural e da extensão do capitalismo ao campo da cultura. Em suma, uma forma breve que tende a economizar e condensar meios e recursos narrativos, e que tem como traços fundamentais de sua elaboração a contração e a concentração.

Passa à forma literária, segundo Jolles (1930: 181), no momento em que os irmãos Grimm deram a uma coletânea de narrativas o título de Kinder-und Hausmãrchen [Contos para Crianças e Famílias], considerando que aplicaram um termo que vinha sendo usado há muito por diversos autores com matiz particular. Apesar disso, fora a coletânea dos Grimm que reuniu toda aquela diversidade num conceito unificado, e que passou a ser a base de outras ulteriores do século XIX.

O conto como gênero literário em nossa civilização, talvez, seja o mais antigo, iniciado com as epopéias mais remotas, transformando-se com o passar do tempo. A formação de uma comunidade cristã amplia os auditórios para as histórias da vida corrente ou para as narrativas prodigiosas. O conto em prosa floresce dessa comunidade. Ao lado de Carlos Magno e seus pares, de Artur, de Merlin, dos cavaleiros da Távola Redonda, surgia o conto edificante pela aventura divertida, anedota graciosa, episódio histórico. As peregrinações e as Cruzadas espargem por toda parte esse pólen miraculoso nas histórias que iam amenizando a monotonia das viagens longas, a vigília nos refeitórios dos conventos, as noites intermináveis nos passadiço dos navios, as conversas nas estalagens, ao acaso dos encontros fortuitos (Sobrinho, 1960: 03). Pelo assunto versado, podem ser identificados nessa fase cinco modelos de contos: popular, infantil, galante, conto-fábula e conto-moral.

Cabe à Itália uma posição de vanguarda na história do conto em que Giovanni Boccaccio avulta como figura central sob o tom lúdico. Irreverente até mesmo com a Igreja, encontra na satisfação dos instintos a razão profunda da própria vida, agradando, por isso, a uma sociedade cansada de lutas, sofrimentos, horrores das epidemias e da pesada disciplina da fé. Sob o modelo do Decameron, multiplicam-se os escritores de contos que passam a ter como tema os novos costumes, como o adultério, a libidinagem. Mesmo na França o gênero bocaciano encontra expansão e acolhimento fervoroso nas coroas da nobreza, nas côrtes libertinas, nos salões acostumados à exaltação dos sentimentos e à satisfação dos instintos.

Lembrado nas célebres histórias das "Mil e Uma noites", no século X, teve seus desdobramentos no modo de narrar, saltando para o século XIV com os contos eróticos 
de Boccaccio, no Decameron. No XVII, aparece com Cervantes e Chaucer, em Novelas exemplares e Contos de Caterburry, respectivamente. Passa ao XVIII com os contos de Perrault, as fábulas de La Fontaine, conquistando contornos mais salientes. Mas não resta a dúvida que foi no século XIX que esta composição textual foi mais estimulada entre outras razões pelo surgimento das oportunidades instauradas pela imprensa e a publicação de contos nos jornais. Aqui, cabe ressaltar nosso autor foco de análise na sequência, pois, Eça de Queirós, na sua carreira diplomática, distante do país, teve diminuída sua irreverência como cidadão português e acentuada a do escritor. $\mathrm{Na}$ Inglaterra, distante da pátria, colaborou em vários jornais de Portugal e do Brasil, apontam Abdala Jr e Paschoalin (1991: 110).

O gênero tratou-se, assim, da narrativa que acompanhou a evolução da imprensa e das publicações periódicas. No Realismo foi comparado ao soneto "em face da sua condensação, do rigor de seu acabamento, da sua unidade e da funcionalidade do desfecho" (LUCAS, 1996: 106). Tipificando-se pela condensação dos meios, sua composição literária revelou algo próximo ao drama pelo manifesto interesse de engendrar situações ou caracteres contrastivos e de conduzir ao desenlace de tensões construídas. Com o esfacelamento do enredo e a desconvencionalização dos caracteres, caminhou-se para a formação do "conto de atmosfera" com uma atenção maior ao processo de escrita, para um referencial menos externo; aproxima-se da expressão poética, comportando-se como um poema.

A valorização e consolidação do conto se devem ao instrumento de veiculação, o jornal, mais precisamente, o periódico. A princípio o jornal não passava de um meio de informação geral, limitado a quatro páginas de formato pequeno com notícias que influíam na marcha dos negócios de cada país. Não havia lugar nesse tipo de periódico para a exposição de narrativas de cunho literário. Isso só ocorre com o aparecimento dos Gabinetes Literários que começaram a surgir desde o século XVIII nos países europeus. Daí por diante, o jornal e o conto passam a caminhar juntos, não havendo dentro da ficção, gênero melhor ajustado aos jornais que o do conto em prosa, fácil de publicar de uma só vez e acessível a todos tanto pela simplicidade do entrecho, como pela linguagem corrente. À medida que o jornal ganha força, multiplicando suas edições, aumentando seu formato e número de páginas de cada exemplar, o conto ganha importância, obtendo, de uma só vez, dois triunfos: o da difusão e o da consagração 


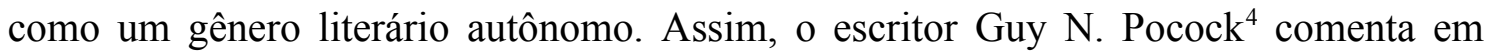
prefácio de uma coletânea inglesa de contos que

[...] cataratas de histórias curtas surgem, semanalmente, diariamente, talvez de hora em hora, dos prelos ingleses e americanos, de tal modo que uma revista conhecida chegou a dizer que se todas as histórias curtas publicadas num ano fossem colocadas em linha, iriam de Fleet Street a Marte.

Figura famigerada no gênero consta no nome do americano Edgar A. Poe. Historicamente, a nação do autor encaminhava-se para o industrialismo; Poe assistiria ao início dos conflitos abolicionistas e escravistas, aos prelúdios da guerra entre o Norte e o Sul. Paralelamente a este clima de progresso, a literatura se refugiava em pacatos moldes do século XVIII, aspirando, portanto, às elegâncias retóricas dos romances inglês e francês. Mas Poe se opõe à extensão do romance, que não pode ser lido de uma só vez, fazendo o leitor se ver "privado da imensa força que deriva da totalidade"; o conto, ao contrário, "breve, permite ao autor desenvolver plenamente seu propósito" 5 . Desse modo, percebe, pioneiramente, o rigor que exigia o conto como gênero autônomo, surgido na França com Mérimée e Balzac, e que as diferenças deste em relação ao romance não eram só uma questão de tamanho. Descobre a "fórmula" de construir um conto, de diferenciá-lo de um capítulo de romance, dos relatos autobiográficos, das crônicas romanceadas do seu tempo.

Compreendeu que a eficácia de um conto depende da sua intensidade como acontecimento puro, isto é, que todo comentário ao acontecimento em si [...] deve ser radicalmente suprimido. Cada palavra deve confluir, concorrer para o acontecimento, para a coisa que ocorre e esta coisa que ocorre deve ser só acontecimento e não alegoria [...] ou pretexto para generalizações psicológicas, éticas ou didáticas. (CORTÁZAR, 1974: 122)

A economia não é somente questão de tema, de ajustar episódio ao seu miolo, mas de fazê-lo coincidir com a sua expressão verbal; logo, todo rodeio torna-se desnecessário para ele. Dessa visão partilha o escritor J. Cortázar; coloca que, na medida em que o romance acumula progressivamente seus efeitos no leitor, um bom conto é aquele incisivo, mordente, sem trégua desde as primeiras frases.

\footnotetext{
${ }^{4}$ POCOCK apud SOBRINHO, 1960: 09.

${ }^{5}$ Poe apud CORTÁZAR, 1974: 121.
} 
A título de complementação discursiva do tópico, convém mencionar que, no Brasil, a história do conto antecede a fase da modernização com algumas poucas reflexões teóricas. Em 1894, Araripe Jr n'A Semana publicou o artigo "Movimento literário de 1893", onde tratou da autonomia do conto perpetuando a análise de José Oiticica em "Teoria do conto", que restringiu as características do gênero a ser sintético, monocrônico e dar relevo a um incidente não comum da vida. Para Edgar Cavalheiro, o pai do conto brasileiro seria Norberto de Souza e Silva, cujo trabalho - As duas órfãs que lhe garantiria tal título teria aparecido em 1841 num folheto de cerca de 30 páginas. Onze anos depois reúne o conto a três outros, publicando o volume Romances e novelas. Já Herman Lima em monografia crítica pontua que somente em 1880 o conto brasileiro, desde os seus começos, teve como mestre Machado de Assis, que talhou o gênero nos melhores cânones dos moldes franceses. De qualquer forma, é arriscado precisar o ano em que apareceu o conto no Brasil dada à amplitude do gênero e a dificuldade de um conceito restrito ou nítido. À margem do debate político iam surgindo sátiras e apólogos, que não raro se revestiam da feição do conto. O Farol Paulistano, de 7 de março de 1827, publica um conto de Le Sage; e em outubro traduzia um conto da Minerva Francesa. A Astrea acompanha de perto esses modelos, divulgando apólogos, diálogos e anedotas que podiam ser enquadrados entre as primícias do conto.

A fundação de $O$ Chronista, em Pernambuco, dirigido por Justiniano da Rocha, em 1836, é fator decisivo para a ampliação do gênero. A partir dessa iniciativa, o Diário do Rio, meramente noticioso, cria em novembro de 1837 uma seção intitulada "Variedades Literárias", e assim sucessivamente multiplicam-se os folhetos destinados à divulgação dos contos.

Permanecendo na ideia de "paternidade", Edgar Cavalheiro (1952) expõe Valdomiro Silveira como o pai do conto regional brasileiro. Embora a obra "Os Caboclos" tenha aparecido somente em 1920, o prefácio de Agenor Silveira para esta edição esclarece que o primeiro trabalho regional de Silveira, "Rabicho", surgiu no Correio Popular, de São Paulo, no ano de 1891, se bem que todas as histórias de "Os Caboclos" foram compostas e publicadas entre 1897 e 1906. Valdomiro traz para a ficção cenas e tipos, costumes e paisagens da roça e, sobretudo, o linguajar do caboclo. Mais do que um léxico e sintaxe caboclas, construiu um regionalismo não de vocabulário, e sim de sentido. Fazendo-se intérprete da alma cabocla, Valdomiro 
Silveira sentiu que somente poderia ser-lhe fiel, se nada deturpasse, isto é, se conservasse, além da língua, os próprios sentimentos dos seres humanos, as paisagens que o cercam, o "clima" que habitam (p. 10).

Silvio Romero (1954: 12) expõe a tipologia dos contos em quatro: conto de encantamento (Conto de Fadas, estórias da Carochinha), conto etiológico, como o que registra peculiaridade física ou costume da personagem, conto acumulativo estruturado em episódios sucessivamente encadeados (contos sem fim e trava-línguas, por exemplo) e conto de adivinhação em que o motivo solucionador é um enigma que o herói resolve (p. 32-3). O conto popular ou tradicional, título preferido pelos folcloristas de Portugal e do Brasil, é uma categoria lembrada por Cascudo (2000), que o define como o mais amplo e expressivo. Surge com Perrault, em 1697, nos Contes du Temps Passé, irradiando uma fase que quebra, em parte, o desdém com que eram recebidas as produções de fundo popular, que, antes, só interessavam aos etnógrafos, folcloristas. Revela informação histórica, etnográfica, sociológica, jurídica, social, o que o faz um documento vivo, denunciando costumes, ideias, mentalidades, decisões e julgamentos.

\section{II - Corpus analítico}

O Primo Basílio (1878), literariamente, faz parte da fase naturalista de Eça de Queirós, aquela em que lhe interessa o caso típico da vida social, seu significado coletivo, e não a particularidade individual, escrevem os críticos citados de História social da literatura portuguesa (1990: 111). Logo nas primeiras páginas dessa obra (1997), temos indícios de um possível adultério de Luisa: “Era a primeira vez que (Jorge) se separava de Luisa". Em seguida, nos é dada a informação de que o primo Basílio chegaria do Brasil. A ausência do marido e a chegada do parente, que depois saberemos tratar-se de um ex-namorado da protagonista, nos induz à ideia de um possível adultério. Semelhantemente, em "No moinho", temos o abandono de Maria da Piedade que, embora tenha o marido em casa, este não pode ser considerado um companheiro ou amante, mas apenas um enfermo que conta com os cuidados da dedicada esposa. Tanto no conto quanto no romance, Eça de Queirós cria uma circunstância de sofrimento ou, pelo menos, de insatisfação das duas mulheres que será exacerbada com a chegada do Primo Basílio, no primeiro caso, e do Primo Adrião, no 
segundo. No entanto, o romance apresenta indícios de uma possível traição de Luisa, enquanto que no conto o leitor é pego por knock-out, isto é, a traição da personagem não era algo tão esperado, mesmo esta sendo apresentada como mulher resignada. Maria era piedosa e o adultério torna-se uma surpresa ao leitor desatento que não fora capaz de captar os detalhes do sofrimento da personagem que poderiam levá-la ao adultério.

No romance, a descrição da empregada Juliana que ocorre às primeiras páginas da obra também induz o leitor a aguardar uma provável morte desta por motivos cardíacos, ou algum ataque dessa natureza:

Devia ter quarenta anos; era muitíssimo magra. As feições, miúdas, espremidas, tinham a amarelidão de tons baços das doenças de coração. Os olhos grande encovados, rolava numa inquietação, numa curiosidade, raiados de sangue, entre pálpebras sempre debruadas de vermelho. (QUEIRÓS, 1997: 11)

Se os personagens populares na obra de Eça de Queirós só aparecem de forma rápida ou formando a paisagem social, sem uma função mais importante na trama, o mesmo não se pode asseverar em relação à Juliana. Nessa exceção, a personagem é “difícil de ser entendida no quadro da vida portuguesa", pois lhe falta "a tipicidade pretendida pela estética realista naturalista" (ABDALA Jr. \& PASCHOALIN, 1990: 112), cujas principais características versam em torno da crítica ao tradicionalismo vazio da sociedade portuguesa; crítica ao conservadorismo da Igreja; visão objetiva e natural da realidade; preocupação com a reforma (e não com a revolução da sociedade com o objetivo de democratizar o poder político); e representação da vida contemporânea, procurando mostrar todos os seus detalhes significativos (id., p. 105).

Além das informações sobre a saúde de Juliana, também nos é informado seu caráter curioso e aproveitador. A narração faz supor que, ao menor descuido de Luisa, a empregada iria se aproveitar da situação em favor próprio. A chantagem feita pela empregada não foi, portanto, novidade para o leitor atento:

E muito curiosa; era fácil encontrá-la, de repente, cosida por detrás de uma porta com a vassoura a prumo, o olhar aguçado. Qualquer carta que vinha era revirada, cheirada... Remexia sutilmente em todas as gavetas abertas; vasculhava em todos os papéis atirados. Tinha um modo de andar ligeiro e surpreendedor. Examinava as visitas. Andava a busca de um segredo, de um bom segredo! Se lhe caía um nas mãos! (QUEIRÓS, 1997: p. 72) 
Diferente das longas descrições, que apresentam as possibilidades futuras, dos vestígios, que orientam a interpretação ao final do romance, o conto "No Moinho”, apesar de certas similaridades em nível de enredo, não mostra ao leitor o caráter de Maria da Piedade. Só nos é dado saber que se trata de uma "senhora modelo" na vila em que reside, enfermeira da própria família, “Uma santa! É o que ela é!”, segundo Nunes, diretor do correio local. No mais, não possuía grandes desejos e distrações, e sua vida se resumia em cuidar dos enfermos - marido inválido, João Coutinho, e filhos doentes, "duas rapariguitas e um rapaz" - e fixar seu olhar na monotonia da paisagem vista através da mesma janela todos os dias, monotonia essa, que refletia sua própria situação de vida. Nota-se que em O Primo Basílio, Luisa também é considerada "um anjinho cheio de dignidade" e "muito boa dona de casa" de acordo com o personagem Sebastião (p. 12). Como o conto tende a ser "econômico" quanto a sua construção, as palavras assim empregadas pelo contista têm valor fundamental para o seu entendimento, soando como chaves que abrem a história. Dessa forma, o nome Maria da Piedade já carrega lexical e intrinsecamente suas características. O primeiro, Maria, nos remete à mãe de Jesus, símbolo da virgindade, da pureza e da simplicidade, de uma santa. Já Piedade está relacionada ao caráter bom, resignado, piedoso, pois “era, para a gente que às tardes ia fazer o giro até ao moinho, um encanto sempre novo vê-la por trás da vidraça, entre as cortinas de cassa, curvada sobre a sua costura, vestida de preto, recolhida e séria" (p. 84, grifos nossos), e "se o marido de dentro chamava desesperado, ou um dos pequenos choramingava, lá limpava os olhos, lá aparecia com a sua bonita face tranquila, com alguma palavra consoladora, compondo a almofada a um, indo animar o outro, feliz em ser boa." (p. 84)

Dada sua vida uniforme e pacata, na qual a

mesma paisagem que ela via da janela era tão monótona como a sua vida: em baixo a estrada, depois uma ondulação de campos, uma terra magra plantada aqui e além de oliveiras e, erguendo-se ao fundo, uma colina triste e nua, sem uma casa, uma árvore, um fumo de casal que pusesse naquela solidão de terreno pobre uma nota humana e viva [...]. (p. 84)

em que "Poucas vezes saía", não era de se esperar dela qualquer desvio moral, visto que a personagem, pelo menos até a chegada de seu primo Adrião, "homem célebre", 
"um romancista", cuja fama "apresentava-o como uma personalidade interessante, um herói de Lisboa, amado das fidalgas, impetuoso e brilhante, destinado a uma alta situação no Estado” (p. 84), não se deixava cativar por sentimentalidades como ocorria com Luisa, que "lia muitos romances, aos 18 anos entusiasmara-se por Walter Scott e pela Escócia; desejara então viver num daqueles castelos escoceses” (p. 16), e idealizava o mundo que lia. No caso desta, ela foi apresentada como romântica e sonhadora desde o começo da história, como se o narrador já estivesse pretendendo incutir em nossas percepções o caráter leviano de Luisa que veria no primo a possibilidade de tornar-se a heroína de um romance, enquanto Maria da Piedade começa a ler romance depois do beijo de Adrião.

Segundo Massaud Moisés (1973), o conto e o romance se diferem no quesito unidade de ação. Para o autor, "o conto constitui uma unidade dramática, uma célula dramática. Portanto, contém um só conflito", no qual "todos os ingredientes" dele "levam a um mesmo objetivo, convergem para o mesmo ponto" (p. 124), enquanto que "o romance apresenta pluralidade dramática, isto é, uma série de dramas, conflitos ou células dramáticas" (p. 190).

Deste prisma, percebemos que ambas as obras analisadas se enquadram nessa concepção: o conto "No Moinho" apresenta apenas uma célula dramática em oposição à obra $O$ Primo Basílio que possui pluralidade de ação.

Essa diferença de construção também pode ser elucidada por um conceito de outro autor, J. Cortázar:

O romance e o conto se deixam comparar analogicamente com o cinema e a fotografia, na medida em que um filme é em princípio uma "ordem aberta", romanesca, enquanto que uma fotografia bem realizada pressupõe uma justa limitação prévia, imposta em parte pelo reduzido campo que a câmara abrange e pela forma com que o fotógrafo utiliza esteticamente essa limitação. (CORTÁZAR, 1993, p. 151)

Todos os elementos do conto de Eça de Queirós nos direcionam ao adultério final de Piedade, pois a ação se constrói em torna da personagem principal e não há conflitos paralelos. A história começa e termina focalizando a vida desta protagonista, suas mudanças, conflitos internos. Há, contudo, um salto temporal, uma vez que a traição só acontece efetivamente após dois anos da visita ao moinho e do beijo de 
Adrião. O fato aproxima-se do conceito de conto apresentado por Cortázar: é como se o adultério em si fosse um recorte da história de Piedade, a fotografia de uma ação fechada.

Já no romance de Eça encontramos mais de uma célula dramática. Embora o adultério de Luisa com o primo seja a ação principal, não se pode ignorar a luta de classes que há entre Luisa e sua antagonista Juliana. Ao se apoderar da carta adúltera, Juliana tem "a faca e o queijo" nas mãos, isto é, em uma sociedade de dominantes e dominados, a empregada inverte os papéis e Luísa passa a ser sua subalterna, satisfazendo seus desejos. Paralelamente, temos ainda o que poderíamos chamar de terceira ação: a sociedade lisboeta representada pelos personagens secundários, que reproduzem a imagem de tipos sociais como o próprio Eça de Queirós (1997, p. 413) descreve em uma carta direcionada a Teófilo Braga:

[...] por outro lado a sociedade que cerca esses personagens - o formalismo oficial (Acácio), a beatice parva de temperamento irritado (D. Felicidade), a literaturinha acéfala (Ernestinho), o descontentamento azedo, e o tédio da profissão (Julião) e às vezes quando calha, um pobre bom rapaz (Sebastião). Um grupo social, em Lisboa, compõe-se, com pequenas modificações, destes elementos dominantes. Eu conheço vinte grupos assim formados.

Massaud acrescenta, ao definir a estrutura do conto, que neste "o lugar geográfico, por onde as personagens circulam, é sempre de âmbito restrito" (p. 113) e "poucas são as personagem que intervêm no conto, como decorrência da unidade de ação, tempo, lugar e tom" (p.114). "No Moinho" apresenta, assim, tais características, já que a narrativa desenvolve-se em lugar restrito, na casa de Piedade, no moinho, na vila, enquanto que no romance, por sua vez, há uma infinidade de lugares apresentados: a casa de Luisa, a rua, a casa de Leopoldina, a casa de Sebastião, o teatro, a igreja, enfim. Quanto ao número de personagens, o mesmo pode ser percebido: no conto temos apenas Maria da Piedade como centro da trama com pouquíssimos personagens, Adrião e outros que gravitam ao redor da protagonista.

Conclui-se, portanto, que Eça de Queirós, valendo-se da estrutura do conto, foi capaz de produzir um enredo muito semelhante ao do romance O Primo Basílio, com direito à crítica aos romances românticos, considerados indutores de adultério. Percebese, assim, a capacidade do escritor em demonstrar que menos pode ser mais. Ou seja, o 
autor usa gêneros distintos para trabalhar um mesmo tema (a falsidade da ideia de que o amor é uma saída à mediocridade da vida burguesa), sendo que escolhe o romance, por sua extensão, para fazer uma ampla crítica à leitura de romances que instiga a traição no matrimônio, isto é, para falar de como o desejo de romper com a convenção social burguesa é algo sistêmico e interiorizado no próprio modo de vida burguês, enquanto escolhe o conto para falar de uma ruptura abrupta dessa convenção, mas que, em última instância, resulta da mesma ilusão de escapar pelo amor à mesquinharia da vida burguesa.

\section{Referências Bibliográficas}

ABDALA Jr. Benjamin \& PASCHOALIN, Maria Aparecida. História social da

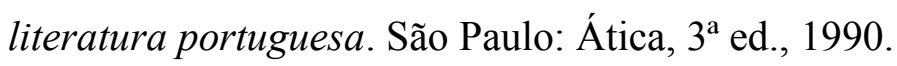

CASCUDO, Luís C. Contos tradicionais do Brasil. 2000.

CAVALHEIRO, E. Evolução do conto brasileiro. 1952.

CORTÁZAR, Júlio. “Alguns aspectos do conto". In: . Valise de Cronópio.

São Paulo. Perspectiva, $2^{\mathrm{a}}$ ed., 1974.

LISPECTOR, Clarice. “Tentação”. In: Felicidade clandestina. Rio de Janeiro: Rocco, 1998.

LUCAS, Fábio. “O conto no Brasil moderno”. In: PROENÇA FILHO, Domício (org.). O livro do seminário. Rio de Janeiro: LR Editores, 1996.

MOISÉS, Massaud. A Criação Literária. São Paulo. Melhoramentos, $6^{\mathrm{a}}$ ed., 1973.

QUEIRÓS, Eça de. O Primo Basílio. São Paulo. Publifolha, 1997. 
ROEFERO, Elcio Luís. Imobilidade e solidão: A “Tentação" de Clarice Lispector.Te se de Doutorado. Universidade de São Paulo, s/d. 